\title{
Resin Infiltration of Non-Cavitated Caries Lesions: A Systematic Review
}

\author{
Sophie Doméjean ${ }^{\mathrm{a}-\mathrm{c}}$ Raphaël Ducamp ${ }^{\mathrm{a}-\mathrm{c}}$ Stéphanie Léger ${ }^{\mathrm{d}}$ \\ Christopher Holmgren ${ }^{\mathrm{e}}$ \\ ${ }^{a}$ Centre de Recherche en Odontologie Clinique EA 4847, b Service d'Odontologie, CHU Clermont-Ferrand, and ${ }^{C}$ UFR \\ d'Odontologie, Université de Clermont 1, Clermont-Ferrand, 'D Département de Mathématiques, University Blaise \\ Pascal, Aubière, and ${ }^{\mathrm{e} A i d e}$ Odontologique Internationale, Montrouge, France
}

\section{Key Words}

Resin infiltration · Non-cavitated caries lesions .

Inhibition of caries progression

\begin{abstract}
Objective: The aim of this systematic review was to evaluate the in vivo scientific evidence of the ability of resin infiltration (RI) to arrest non-cavitated caries lesions. Materials and Methods: The PubMed database was searched for randomized controlled trials that evaluated the in vivo effect of RI versus placebo or other preventive treatment on the progression of caries lesions. The keywords used were 'resin infiltration, dental caries', 'resin infiltration, carious lesions', 'resin infiltration, caries lesions', 'caries infiltration' and 'Icon DMG' with the 'clinical trial' filter activated. Among the 14 articles originally identified with these keywords, only 4 (related to 3 different in vivo studies) were included for this review. Results: All 4 articles reported on proximal caries lesions. One study had been conducted on 48 high-caries-risk children while the other $3(n=22,22$ and 39, respectively) concerned moderate- and low-caries-risk adolescents and adults. The quality of the studies was assessed to be high with respect to randomization, split-mouth design and blinding. All the included studies showed significant differ-
\end{abstract}

ences in caries progression between test and control/placebo groups, indicating that RI may inhibit the carious process. Conclusion: This systematic review revealed that RI appeared to be an effective method to arrest the progression of non-cavitated caries lesions. Additional, long-term studies are required.

(c) 2015 S. Karger AG, Basel

\section{Introduction}

Approaches for the management of dental caries have changed dramatically in recent years, evolving from the traditional, largely restorative treatment approach to a preventive approach, non-invasion or minimal invasion [1]. In view of a better understanding of the caries process, modern management approaches should aim towards preventing the disease, managing the caries risk and detecting caries lesions as early as possible in order to avoid invasive treatment, but, when indicated, use the least invasive methods [1].

Several approaches have been proposed for the noninvasive management of non-cavitated caries lesions, also known as initial or early caries lesions (from the first signs of demineralization through to the presence of a dentine

\begin{tabular}{ll}
\hline KARGER 125:s & $\begin{array}{l}\text { ( ) 2015 S. Karger AG, Basel } \\
1011-7571 / 15 / 0243-0216 \$ 39.50 / 0 \quad \text { Karger }\end{array}$ \\
$\begin{array}{l}\text { E-Mail karger@karger.com } \\
\text { www.karger.com/mpp }\end{array}$ & $\begin{array}{l}\text { Thisis an Open Access article licensed under the terms of the } \\
\text { Creative Commons Attribution-NonCommercial 3.0 Un- } \\
\text { ported license (CC BY-NC) (www.karger.com/OA-license), } \\
\text { applicable to the online version of the article only. Distribu- } \\
\text { tion permitted for non-commercial purposes only. }\end{array}$
\end{tabular}

Prof. Sophie Doméjean

UFR d'Odontologie, Université de Clermont 1

2 rue de Braga

FR-63100 Clermont-Ferrand (France)

E-Mail sophie.domejean@udamail.fr 
lesion without cavitation). These include the remineralization of the lesion with fluoride [2] and casein phosphopeptide amorphous calcium phosphate [3], or the use of therapeutic sealants for occlusal lesions [4]. Another noninvasive alternative treatment is based on experiments conducted by Robinson et al. [5] on caries infiltration with resorcinol-formaldehyde resin. This concept has been modified and commercially developed in Germany for the management of non-cavitated caries lesions; the porosities of an enamel lesion are infiltrated with a lowviscosity resin, a technique known as 'resin infiltration' (RI) $[6,7]$. In contrast to the sealing of caries lesions that depends upon the external occlusion of the lesion with the sealant material, the potential caries-inhibiting effect of RI is dependent on the occlusion of the pores within the body of the caries lesion. Other indications for RI, relating to the presence of tissue porosity, namely amelogenesis imperfecta, molar incisor hypomineralization, fluorosis and white spots, have also been suggested [8$11]$.

Scientific evidence for efficacy should underline the implementation of new therapeutic strategies in everyday clinical practice. Systematic reviews serve to compare the results obtained in clinical studies on a specific topic, for instance, to assess the efficacy of a newly introduced therapy. The aim of this review was to evaluate the in vivo scientific evidence regarding the ability of RI to arrest non-cavitated caries lesions (occlusal and proximal).

\section{Materials and Methods}

\section{Data Collection}

The PubMed database was searched in September 2014 for randomized controlled trials that evaluated the in vivo effect of RI on caries lesion progression. The search was undertaken with the following keywords: 'resin infiltration, dental caries', 'resin infiltration, carious lesions', 'resin infiltration, caries lesions', 'caries infiltration' and 'Icon DMG' with the 'clinical trial' filter activated.

The articles were included for review on the basis of their compliance with the inclusion criteria, namely (1) the title or abstract was relevant to the topic and (2) they reported an in vivo trial.

Each article that complied with the inclusion criteria was evaluated by two authors (R.D. and S.D.) for study quality [12], namely the generation of the randomization sequence (allocation), the study design, the blind outcome assessment, the control group and the completeness of follow-up (i.e. the drop-out rate).

\section{Relative Risk for Caries Progression}

We calculated the relative risk (RR) and 95\% confidence interval (CI) for caries progression in the test group (i.e. the group who received RI) compared with the control/placebo groups for each of the included studies.

Resin Infiltration of Caries Lesions
Table 1. Results of the search

References

\begin{tabular}{ll} 
& References \\
\hline Included articles & $\begin{array}{l}\text { Ekstrand et al., 2010 [13] } \\
\text { Martignon et al., 2012 [14] } \\
\text { Paris et al., 2010 [15] } \\
\text { Meyer-Lueckel et al., 2012 [16] }\end{array}$ \\
\hline $\begin{array}{ll}\text { Excluded articles } \\
\text { Off the topic }\end{array}$ & Yazicioğlu and Ulukap1, 2014 [17] \\
& Vailati et al., 2013 [18] \\
& Salomon et al., 2012 [19] \\
& Krzemiński et al., 2011 [20] \\
& Liu et al., 2011 [21] \\
\hline RI and aesthetics & Knösel et al., 2013 [22] \\
\hline $\begin{array}{l}\text { RI and shear bond strength of metal } \\
\text { orthodontic brackets }\end{array}$ & Hammad and Enan, 2013 [23] \\
\hline RI ex vivo study & Soviero et al., 2013 [24] \\
\hline RI in situ study & Paris and Meyer-Lueckel, 2010 [25] \\
\hline $\begin{array}{l}\text { RI and the effect of two different acid } \\
\text { etching agents }\end{array}$ & Paris et al., 2010 [26] \\
\hline
\end{tabular}

${ }^{a}$ References 15 and 16 reported on the same study but for two different study periods, i.e. 18 and 36 months, respectively.

\section{Results}

\section{Results of the Search}

The results of the search are presented in table 1. Of the 14 articles originally identified with the search keywords listed earlier, only 4 met all the inclusion criteria and were retained for this review. The remaining 10 articles were excluded for the following reasons: 5 were unrelated to the topic of RI, 1 was related to RI and aesthetics, 1 to RI and the shear bond strength of metal orthodontic brackets, 1 was an ex vivo study, 1 was an in situ study and the last one was a report on two different acid etching agents.

\section{Included Studies}

The 4 included articles reported on the use of RI for arresting proximal caries lesions. The information assessed concerning the quality aspects of these 4 studies is given in table 2. All studies used a split-mouth design, a randomized allocation, a blinded outcome assessment and a control group/groups, with drop-outs being taken into account.

The test group was characterized by RI used in conjunction with fluoride varnish (FV) in the study by Ekstrand et al. [13] and RI alone in the other studies [1416]. All of the included studies compared RI/RI + FV to 1 or 2 other groups, respectively, 'control: FV', 'placebo: 
Table 2. Quality assessment of included studies

\begin{tabular}{llll}
\hline & Ekstrand et al., 2010 [13] & Martignon et al., 2012 [14] & $\begin{array}{l}\text { Paris et al., 2010 [15] } \\
\text { Meyer-Lueckel et al., 2012 [16] }\end{array}$ \\
\hline Randomization & Yes & Yes & Yes \\
\hline Study design & Split-mouth & Split-mouth & Split-mouth \\
\hline Blind outcome assessment & Yes & Yes & Yes \\
\hline Test group(s) & RI + FV & RI & RI \\
\hline Control/placebo group(s) & FV & Sealant & Water application \\
\hline Drop-outs & $6 / 48(12.5 \%)$ & Microbrush & $2 / 22(9.1 \%)$ \\
\hline
\end{tabular}

Table 3. Study design: population, outcome assessment and period

\begin{tabular}{|c|c|c|c|}
\hline Patients & $\begin{array}{l}48 \text { children } \\
\text { (mean age: } 7 \text { ) }\end{array}$ & $\begin{array}{l}39 \text { adolescents and young } \\
\text { adults (mean age: } 21 \text { ) }\end{array}$ & 22 young adults (mean age: 25 ) \\
\hline Level of caries risk & High & $\begin{array}{l}\text { Low: } 46 \% \\
\text { moderate: } 28 \% \\
\text { high: } 26 \%\end{array}$ & Moderate \\
\hline $\begin{array}{l}\text { Lesions considered for outcome } \\
\text { (unit of analysis) }\end{array}$ & 42 lesion pairs & 37 groups of 3 lesions & 26 lesion pairs \\
\hline Outcome assessment & $\begin{array}{l}\text { PWC } \\
\text { ICDAS score progression }\end{array}$ & PWC & $\begin{array}{l}\text { PWC } \\
\text { DSR }\end{array}$ \\
\hline Follow-up duration & 12 months & 36 months & $\begin{array}{l}18 \text { months }[15] \\
36 \text { months }[16]\end{array}$ \\
\hline
\end{tabular}

DSR = Digital subtraction radiography ICDAS = International Caries Detection and Assessment System; PWC = pair-wise comparison.

water application' and 'control: sealant, placebo: microbrush'.

Details of the study population (number of patients, age, level of caries risk, primary/permanent teeth), the outcome assessment and the follow-up duration are given in table 3. The unit of analysis was the related lesion pair or a group of three lesions. The outcome variable was the proportion of lesions that progressed during the study period. In all 4 articles, outcomes were assessed by pairwise comparison of the depth of the lesions scored on bite-wing radiographs. Meyer-Lueckel et al. [16] and Paris et al. [15], however, considered this direct scoring of lesion progression to be a secondary end point and used digital subtraction radiography of the scanned images as the primary end point. Martignon et al. [14] also used digital subtraction radiography at the 1 -year review but not thereafter. Ekstrand et al. [13] based their assessment on radiographs and the collection data with a direct assessment using scoring according to the International Caries Detection and Assessment System (ICDAS).

The outcomes for each of the included studies, the RR and the 95\% CI for caries progression in the test group (RI group) compared with the other treatment alternatives or placebo are presented in table 4 . All 4 articles showed significant differences in caries progression between the test and control/placebo groups, indicating that RI might inhibit the carious process. RR for proximal caries progression, assessed by pair-wise comparison, ranged from 0.11 to 0.8 . RR was, respectively, 0.11 (95\% CI $0.01-$ 0.82 for RI vs. water), 0.46 (95\% CI $0.28-0.77$ for RI vs. 
microbrush) and 0.8 (95\% CI $0.44-1.47$ for RI vs. sealant) among moderate- and high-caries-risk adults at 36 months, and 0.38 (95\% CI 0.2-0.7) among high-cariesrisk children (RI + FV vs. FV) at 12 months.

\section{Discussion}

This systematic review revealed that RI appeared to be an effective method to arrest the progression of non-cavitated caries lesions. The calculated RR for the progression of proximal caries across the 4 studies included ranged from 0.11 to 0.8 among moderate- and high-caries-risk adults at 36 months and among high-caries-risk children. Despite the small sample sizes, ranging from 22 $[15,16]$ to 48 [13], significant differences were found between the control and test groups with fewer proximal lesions progressing in those managed with RI (alone or combined with FV).

The RR and the odds ratio (OR) were the two most widely used measures of association in epidemiology. A recent publication by Schmidt and Kohlmann [27] reports when to use OR and RR. They observed that direct computation of RR is feasible if meaningful prevalences or incidences are available and that cohort study designs allow for the direct calculation of RR from incidences. The situation is more complicated for case-control studies; if meaningful prevalences or incidences are not available, the OR provides a valid effect measure. Computationally, both approaches lead to the same result, but, unfortunately, ORs are often interpreted as if they were equivalent to $\mathrm{RR}$, which ignores their actual meaning, i.e. as a ratio of odds. This inaccuracy can lead to potentially serious problems because the OR always overestimates the RR.

These 4 protocol studies fulfilled CONSORT (Consolidated Standards of Reporting Trials) requirements [12]. All 4 included a sample size calculation. This calculation was based on parameters from previous studies: a study on sealing proximal lesions in adult patients [28] for the Martignon et al. [14], Paris et al. [15] and MeyerLueckel et al. [16] studies, and a formula for testing differences in proportions for the paired-sample design by Connor [29] in the Ekstrand et al. [13]study. The dropout rate recorded in the included studies ranged from 5.1 to $12.5 \%$, allowing for relevant results and conclusions as these were all $<20 \%$. The split-mouth study design used for all of the included studies is often used in dental research to test different interventions because it has the advantage of enabling an individual to serve as both sub-
Table 4. Results: lesion progression in test and control groups and RR (95\% CI) for caries progression

\begin{tabular}{|c|c|c|c|}
\hline \multicolumn{4}{|c|}{ Progression differences between test and control or placebo treatment } \\
\hline At 12 months & & & Ekstrand \\
\hline PWC & & $\mathrm{p}<0.001$ & et al. [13] \\
\hline $\mathrm{RI}+\mathrm{FV}$ & $23.1 \%$ & & \\
\hline FV & $61.5 \%$ & & \\
\hline ICDAS score & & $\mathrm{p}=0.002$ & \\
\hline $\mathrm{RI}+\mathrm{FV}$ & $31 \%$ & & \\
\hline $\mathrm{FV}$ & $66.7 \%$ & & \\
\hline At 36 months & & & Martignon \\
\hline PWC & & & et al. [14] \\
\hline RI & $32 \%$ & & \\
\hline Sealants & $41 \%$ & & \\
\hline Microbrush & $70 \%$ & & \\
\hline RI vs. microbrush & & $\mathrm{p}=0.0012$ & \\
\hline Sealant vs. microbrush & & $\mathrm{p}=0.0291$ & \\
\hline At 18 months & & & Paris et al. \\
\hline PWC & & $\mathrm{p}=0.063$ & {$[15]$} \\
\hline RI & $3.7 \%$ & & Meyer- \\
\hline Water & $22.2 \%$ & & Lueckel et \\
\hline DSR & & $\mathrm{p}=0.021$ & al. [16] \\
\hline RI & $7 \%$ & & \\
\hline Water & $37 \%$ & & \\
\hline At 36 months & & & Paris et al. \\
\hline PWC & & $\mathrm{p}=0.008$ & {$[15]$} \\
\hline RI & $4 \%$ & & Meyer- \\
\hline Water & $35 \%$ & & Lueckel et \\
\hline DSR & & $\mathrm{p}=0.002$ & al. [16] \\
\hline RI & $4 \%$ & & \\
\hline Water & $42 \%$ & & \\
\hline
\end{tabular}

RR for caries progression in the test group(s) compared with the control group $(\mathbf{9 5 \%} \mathrm{CI})$

At 12 months

Ekstrand

PWC

$\mathrm{RI}+\mathrm{FV}$ vs. FV

ICDAS score

$\mathrm{RI}+\mathrm{FV}$ vs. FV $\quad 0.46(0.28-0.77)$

\begin{tabular}{|c|c|c|}
\hline \multicolumn{2}{|l|}{$\begin{array}{l}\text { At } 36 \text { months } \\
\text { PWC }\end{array}$} & \multirow[t]{4}{*}{$\begin{array}{l}\text { Martignon } \\
\text { et al. [14] }\end{array}$} \\
\hline RI vs. microbrush & $0.46(0.28-0.77)$ & \\
\hline Sealant vs. microbrush & $0.58(0.37-0.9)$ & \\
\hline RI vs. sealant & $0.8(0.44-1.47)$ & \\
\hline $\begin{array}{l}\text { At } 18 \text { months } \\
\text { PWC }\end{array}$ & & $\begin{array}{l}\text { Paris et al. } \\
\text { [15] }\end{array}$ \\
\hline RI vs. water & $0.17(0.02-1.29)$ & Meyer- \\
\hline DSR & & Lueckel et \\
\hline RI vs. water & $0.2(0.05-0.83)$ & al. [16] \\
\hline $\begin{array}{l}\text { At } 36 \text { months } \\
\text { PWC }\end{array}$ & & $\begin{array}{l}\text { Paris et al. } \\
{[15]}\end{array}$ \\
\hline RI vs. water & $0.11(0.01-0.82)$ & Meyer- \\
\hline DSR & & Lueckel et \\
\hline RI vs. water & $0.09(0.01-0.65)$ & al. [16] \\
\hline
\end{tabular}

DSR = Digital subtraction radiography; ICDAS = International Caries Detection and Assessment System; PWC = pair-wise comparison. 
ject and control, thereby reducing inter-subject variability. It does, however, have limitations, for instance, the need to use appropriate test statistics as well as the potential for problems to arise when testing agents such as fluoride applications, where there can be a carry-across effect to adjacent segments [30]. The 4 articles differed in terms of study design, dentitions and observation periods, and there were some differences in evaluation methods. There was, however, homogeneity between the studies in terms of certain aspects of the protocol and outcome assessment (e.g. the proportion of caries lesions that progressed during the study period shown by pairwise comparison on digitized bite-wing radiographs) which allows for some comparisons to be made. Nevertheless, the compilation of the results was not deemed meaningful because 1 of the included studies was undertaken on primary teeth [13] whereas the others involved permanent teeth where RI was compared to different control/placebo groups [14-16].

The major limitation of this paper is the small sample which was due to the restricted search of the articles published in only one medical database, PubMed. Other databases such as LILACS and SciELO, which include pub- lications in Portuguese and Spanish, or any other language medical databases were not searched. It did not attempt to review aspects such as operator and patient satisfaction with the technique or the cost effectiveness in relation to other approaches.

\section{Conclusion}

This systematic review revealed that the use of RI to arrest the progression of non-cavitated caries lesions is encouraging. This suggests that RI is a promising noninvasive approach and might be considered as an additional option to non-operative and operative treatment approaches. However, high-quality, long-term clinical trials, preferably in general dental practice settings, are required to confirm the efficacy of RI for non-cavitated caries lesions in both deciduous and permanent teeth. In particular, in order to determine long-term benefits, comparisons need to made between RI and remineralization strategies for enamel lesions, and between RI and conventional restorations for dentinal lesions.

\section{References}

$\checkmark 1$ Frencken JE, Peters MC, Manton DJ, et al: Minimal intervention dentistry for managing dental caries - a review: report of a FDI task group. Int Dent J 2012;62:223-243.

-2 Cury JA, Tenuta LM: Enamel remineralization: controlling the caries disease or treating early caries lesions? Braz Oral Res 2009; 23(suppl 1):23-30.

3 Cochrane NJ, Shen P, Byrne SJ, et al: Remineralisation by chewing sugar-free gums in a randomised, controlled in situ trial including dietary intake and gauze to promote plaque formation. Caries Res 2012;46:147-155.

4 Griffin SO, Oong E, Kohn W, et al: The effectiveness of sealants in managing caries lesions. J Dent Res 2008;87:169-174.

5 Robinson C, Hallsworth AS, Weatherell JA, et al: Arrest and control of carious lesions: a study based on preliminary experiments with resorcinol-formaldehyde resin. J Dent Res 1976;55:812-818.

-6 Paris S, Meyer-Lueckel H, Mueller J, et al: Progression of sealed initial bovine enamel lesions under demineralizing conditions in vitro. Caries Res 2006;40:124-129.

7 Paris S, Meyer-Lueckel H, Kielbassa AM: Resin infiltration of natural caries lesions. J Dent Res 2007;86:662-666.
-8 Senestraro SV, Crowe JJ, Wang M, et al: Minimally invasive resin infiltration of arrested white-spot lesions: a randomized clinical trial. J Am Dent Assoc 2013;144:997-1005.

-9 Tirlet G, Chabouis HF, Attal JP: Infiltration, a new therapy for masking enamel white spots: a 19-month follow-up case series. Eur J Esthet Dent 2013;8:180-190.

10 Crombie F, Manton D, Palamara J, et al: Resin infiltration of developmentally hypomineralised enamel. Int J Paediatr Dent 2014;24. 51-55.

11 Munoz MA, Arana-Gordillo LA, Gomes GM, et al: Alternative esthetic management of fluorosis and hypoplasia stains: blending effect obtained with resin infiltration techniques. J Esthet Restor Dent 2013;25:32-39.

12 Schulz KF, Altman DG, Moher D: CONSORT 2010 statement: updated guidelines for reporting parallel group randomised trials. Int J Surg 2011;9:672-677.

13 Ekstrand KR, Bakhshandeh A, Martignon S: Treatment of proximal superficial caries lesions on primary molar teeth with resin infiltration and fluoride varnish versus fluoride varnish only: efficacy after 1 year. Caries Res 2010;44:41-46.
14 Martignon S, Ekstrand KR, Gomez J, et al: Infiltrating/sealing proximal caries lesions: a 3-year randomized clinical trial. J Dent Res 2012;91:288-292.

15 Paris S, Hopfenmuller W, Meyer-Lueckel H: Resin infiltration of caries lesions: an efficacy randomized trial. J Dent Res 2010;89:823-826.

16 Meyer-Lueckel H, Bitter K, Paris S: Randomized controlled clinical trial on proximal caries infiltration: three-year follow-up. Caries Res 2012;46:544-548.

17 Yazıcıoğlu O, Ulukapı H: The investigation of non-invasive techniques for treating early approximal carious lesions: an in vivo study. Int Dent J 2014;64:1-11.

18 Vailati F, Gruetter L, Belser UC: Adhesively restored anterior maxillary dentitions affected by severe erosion: up to 6-year results of a prospective clinical study. Eur J Esthet Dent 2013;8:506-530.

19 Salomon E, Mazzoleni S, Sivolella S, et al: Age limit for infiltration anaesthesia for the conservative treatment of mandibular first molars. A clinical study on a paediatric population. Eur J Paediatr Dent 2012;13:259-262.

20 Krzemiński TF, Gilowski L, Wiench R, et al: Comparison of ropivacaine and articaine with epinephrine for infiltration anaesthesia in dentistry - a randomized study. Int Endod J 2011;44:746-751. 
21 Liu Y, Li N, Qi Y, et al: The use of sodium trimetaphosphate as a biomimetic analog of matrix phosphoproteins for remineralization of artificial caries-like dentin. Dent Mater 2011;27:465-477.

22 Knösel M, Eckstein A, Helms HJ: Durability of esthetic improvement following Icon resin infiltration of multibracket-induced white spot lesions compared with no therapy over 6 months: a single-center, split-mouth, randomized clinical trial. Am J Orthod Dentofacial Orthop 2013;144:86-96.

23 Hammad SM, Enan ET: In vivo effects of two acidic soft drinks on shear bond strength of metal orthodontic brackets with and without resin infiltration treatment. Angle Orthod 2013;83:648-652.

24 Soviero VM, Paris S, Leal SC, et al: Ex vivo evaluation of caries infiltration after different application times in primary molars. Caries Res 2013;47:110-116.

25 Paris S, Meyer-Lueckel H: Inhibition of caries progression by resin infiltration in situ. Caries Res 2010;44:47-54.

26 Paris S, Dörfer CE, Meyer-Lueckel H: Surface conditioning of natural enamel caries lesions in deciduous teeth in preparation for resin infiltration. J Dent 2010;38:65-71.
27 Schmidt CO, Kohlmann T: When to use the odds ratio or the relative risk? Int J Public Health 2008;53:165-167.

28 Martignon S, Ekstrand KR, Ellwood R: Efficacy of sealing proximal early active lesions: an 18-month clinical study evaluated by conventional and subtraction radiography. Caries Res 2006;40:382-388.

29 Connor RJ: Sample size for testing differences in proportions for the paired-sample design. Biometrics 1987;43:207-211.

30 Hujoel PP, DeRouen TA: Validity issues in split-mouth trials. J Clin Periodontol 1992;19: 625-627. 